doctrinal words does not necessarily mean that they are always understood in the same way. One would not guess that the development of the sciences has led to new ways of handling data from the past, from which sacred books could not be exempt, so that a flood of new light has been shed on the Bible. (Officially Islam has not yet come to terms with the same procedures with respect to the Koran, but sooner or later it will have to.)

As instances of what is lacking in this book let us take the work of three major British scholars of our time, James Barr on the Bible, Michael Polanyi on the philosophy of science, and Owen Chadwick on The Secularisation of the European Mind in the Nineteenth Century: none of them has influenced it. Mary Hesse is indeed quoted, but one would not get much idea of the depth of her contribution from what is quoted. Russell's theological comments on the contemporary scene therefore seem somewhat jejune, and his efforts to be fair are taxed at this point. He makes valid criticisms of the simplistic type of scientific positivism, which is by no means dead, but he needs subtler weapons and a greater sense of the reciprocity of the relationship between natural science and Christian theology to do full justice to his theme.

RONALD PRESTON Emeritus Professor of Theology, University of Manchester

\section{Alzheimer's Dementia: Dilemmas in Clinical Research}

Vijaya L Melnick, and Nancy $\mathrm{N}$ Dubler, 312 pages, Clifton, New Jersey, £46.85, Humana Press, 1985

The rationale behind the choice of articles in this collection is obscure. In their introduction the editors imply that the articles emerged from a National Institute of Ageing (NIA) sponsored conference on 'Senile Dementia of the Alzheimer's Type (SDAT) and Related Diseases: Ethical and Legal Issues Related to Informed Consent'. However, whether the book contributors made the same contributions to the conference is not clear. Equally unclear is the background of the contributors. The book lists only their institutions of origin and from this it appears that they are probably predominantly members of the medical and legal professions.

To continue the theme of obscurity it is never clear why the book should concentrate on SDAT when, as the opening chapter points out, this accounts for only 50 per cent of the cases of senile dementia. Contributing to the obliqueness of the book is its general layout which lacks an overall introduction to the ethical issues and a clear statement on why it may be necessary to consider SDAT in isolation. It is not until Part 3 that the 'Historical, Legal and Ethical Background' is considered. The historical perspective presented throughout the book is generally poor, often being merely chronological and not seeking to contextualise. This creates the impression that the legislation on informed consent in the US has functioned to protect the interests of the patient rather than, it appears, to protect medical interests. This naively liberal tone runs throughout the book and generates the suspicion of a hidden agenda which is reinforced by the book's lack of clarity. What constitutes this hidden agenda is, needless to say, unclear.

A question raised early in the book is how can informed consent be obtained from persons whose competence is lacking, questionable or diminishing? Some of the articles do emerge from the general haze of obliquity to attack and go beyond this question, covering the difficult issues of collective control (Andrew Jameton), equity (Harry $\mathbf{R}$ Moody) and proxy consent (Bruce $L$ Miller). These articles are general and removed from some of the parochial concerns of much of the book. Unfortunately little of the book grapples with the limitations of viewing consent as a necessary and sufficient condition for ethical experiments, a point raised by Harry Yeide in his chapter on 'Objectives and Social Structuring'. Nowhere is the issue of the experimentation on marginal groups in the population explored nor the concept of value-free science explicitly questioned.

The parochial nature of many of the chapters limits its relevance to the UK. It must be remembered that the notion of 'informed consent' is a North American concept derived from the decisions of US judges in a series of civil actions since the 1950s. This doctrine is concerned with providing a patient with sufficient information about the intervention to allow him or her to make a rational choice and give true and informed consent (or refusal). This has recently been rejected in the Court of Appeal (and upheld in the House of Lords) as forming no part of British law. Consent to treatment in the UK is based upon a medical standard rather than an autonomous person standard.

However, the position in the UK may be slowly changing. At present there are no legal obligations of consent in the UK. However, the 1983 Mental Health Act brought in new legislation covering consent with certain treatments, psychosurgery for example, requiring consent and a second opinion. The creation of the 1983 MHA was heavily influenced by Larry Gostin who was, significantly, educated in the US legal traditions. The creation of the new Act along with the associated shift from the model of the beneficent doctor to that of the autonomous patient may have future implications for consent outside the realms of psychiatry. Certainly, some of the articles contained in this collection are of value in directing thinking in this area. However, given the nature of the book and its inhibitory cost it may be better to explore the issues in the journals in which the contributors have also outlined their ideas.

DR A P BOARDMAN Lecturer in Psychiatry National Unit for Psychiatric Research and Development, Lewisham Hospital, Lewisham High St, London SE13 6LHC

\section{Law and Morals: Warnock, Gillick and Beyond}

Simon Lee, 98 pages, Oxford, $£ 3.95$ paperback, Oxford University Press, 1986

It may be thought impossible to discuss in any meaningful way the relationship between law and morals in less than 100 pages. Not so, as this volume demonstrates. The book's hallmark is its clarity. There is a concise explanation of the 'law and morals' debate, an exposition of some of the stances which groups take, for example, a Catholic view, a liberal view, the approach taken by Mill (not to do harm to others) and, of course, the Hart/ Devlin debate.

Lee rightly concludes that none of these has a complete answer and he does not presume to provide one. Essentially, his plea is to approach the issues of our time, for example, research on human embryos, surrogacy and contraception by separating differences in relation to predictions and differences which arise from different moral stances. 
The second part of the book examines critically the topics of embryo experimentation, surrogacy, contraception, informed consent, resource allocation, etc and the concluding chapter lists a number of 'Morals' which may be used as guidance in the future. Lee repeats the point that we cannot avoid analysing factual assumptions and moral values in order to see wherein lie the differences in approach on moral issues, and he suggests that democratic decision-making should assist with these processes to a greater extent than is currently done.

The book is short, refreshingly so. The arguments are clearly and thoughtfully presented, refreshingly so. It give the student and the general reader a far better starting point than many others of the genre. Congratulations to the author.

DOUGLAS J CUSINE Department of Conveyancing and Professional Practice of Law, University of Aberdeen, Taylor Building, Old Aberdeen AB9 $2 U B$

\section{Suffering Presence: Theological Reflections on Medicine, the Mentally Handicapped, and the Church}

Stanley Hauerwas, 221 pages, Notre Dame, Indiana, $£ 17.95$ hardback, Notre Dame Press, 1986

This book is really a collection of essays written by Stanley Hauerwas between the years 1978 and 1985. Hauerwas, in making this particular selection, seeks to present a point of view he believes is largely absent from medicine and from medical ethics. He believes that medical ethics, about which he is suspicious, has grown more from the moral confusion in society and medicine than from technological developments in the practice of medicine. To counter such confusion, he intends to recall theology into medical ethics. Theological presuppositions can illuminate the care we offer to one another through medicine (page 6). Moral reflection requires significant examples in order that it may assist the art of medicine.

Hauerwas then proceeds to reflect on the mentally handicapped or retarded in order to develop this point of view. The mentally handicapped are the test of any society's commitment to deal justly and the sign of its understanding of suffering. Hauerwas believes that the intention to prevent all suffering is misguided. His thesis is that human beings are mutually dependent, that need arises from such dependence, and that suffering is a logical facet of such need. Suffering should therefore not be regarded as an unwanted accident in life but as an essential part of it. To this end, he speaks of our 'moral project' in life, and of our incorporation of suffering into that moral project. Our identity as persons depends upon our interpretation and incorporation of suffering. He argues that differentiation between needful and needless suffering is therefore important, but this also has its problems.

Hauerwas challenges the assumption that the mentally handicapped suffer as we do. 'The retarded do not feel or understand their retardation as we do, or imagine we would, but rather as they do' (page 174). Lacking in imagination, we attribute suffering to them, and attempting to avoid the limits of our own sympathy, we avoid their presence. The mentally handicapped thus make us unsure of our own identity. Hauerwas argues that we need to learn to be with the retarded. Indeed, we can learn that they can be a means of grace for us. 'Quite simply, the challenge of learning to know, to be with, and care for the retarded is nothing less than learning to know, be with, and love God' (page 178).

Hauerwas is probably right to question the relevance of medical ethics and its grounding in theology. Whether he has rectified this is another question. The importance of suffering as a theological affirmation can hardly be overstated, particularly when medicine often steps back from dealing with the acceptance of suffering. But Hauerwas does not differentiate clearly enough between the suffering which is needful and that which is needless. From this point of view, the book remains suggestive rather than definitive.

The failure to pursue this thesis rigorously enough means that in the end we are simply left with the affirmation that we must learn to be with those who suffer. We could argue quite effectively that this is so obvious that it does not require such tortured argument.

It is good to see someone dealing with the mentally handicapped from a theological point of view. Clearly, much more work requires to be done in this area. Yet one is struck by the fact that in this collection of essays the mentally handicapped are regarded as the 'test' oour commitment or the 'sign' of our failure, or as the 'means' of our grace One might wish that they would be seen as people, although this is surely what Hauerwas really wants to say. One is referred always to the society, or community, or world, and these displace the central problem. Had Hauerwas dealt more squarely with mental handicap, he might have done the kind of careful analysis which leads to a better appreciation of suffering. As it is, the 'cases' presented are more anecdotal than clinical. Thus he does not succeed in presenting the 'significant examples' which can help moral reflection.

WILLIAM W CLINKENBEARD Minister, Carrick Knowe Parish Church, Saughton Road North, Edinburgh EH12 7AN 